\title{
Title: How can Automatic Identification System (AIS) data be used for maritime spatial planning?
}

Authors: Le Tixerant M. (1), Le Guyader D. (1)., Gourmelon F. (2), Queffelec B (3).

(1) Terra Maris - Place Nicolas Copernic - 29280 PLOUZANE - FRANCE

(2) CNRS UMR LETG, UBO EPHE-PSL U. Angers U. Caen U. Nantes U. Rennes 2 - IUEM - rue Dumont d'Urville - 29280 PLOUZANE - France

(3) UBO UMR AMURE - IUEM - Place Nicolas Copernic - 29280 PLOUZANE - France

Keywords: Automatic Identification System (AIS) - density of maritime traffic - shipping lanes - hierarchical network of maritime routes - sea fishing - spatio-temporal interactions - integrated management - Maritime Spatial Planning (MSP)

\begin{abstract}
Although the importance of Maritime Spatial Planning (MSP) as a concept is now acknowledged and the legal framework is in place, the task of applying it remains a delicate one. One of the keys to success is having pertinent data. Knowing how maritime uses unfold in a spatio-temporal context, and what conflicting or synergistic interactions exist between activities, is crucial. However, this information is especially hard to obtain in a marine environment. As a result this information has often been identified as the missing layer in information systems developed by maritime stakeholders. Since 2002, the Automatic Identification System (AIS) has been undergoing a major development. Allowing for real time geo-tracking and identification for equipped vessels, the data that issues from AIS data promises to map and describe certain marine human activities.

After recapitulating the main characteristics of AIS and the data it provides, this article proposes to evaluate how AIS is currently used in MSP at a European level, and to concisely present a series of methods and results obtained within the framework of several operational research projects. The objective is to illustrate how the AIS data processing and analysis can produce adequate information for MSP: maritime traffic density, shipping lanes and navigation flows, hierarchical network of maritime routes, alleged fishing zones, spatio-temporal interactions between activities (potential conflicting uses or synergies). The conclusion looks in particular at the legal questions concerning the use of AIS.
\end{abstract}




\section{Introduction}

The rapidly increasing use of maritime space is linked to the global human trend for multiplying, diversifying and intensifying sea-related uses and activities (Christie et al., 2014). This trend is especially apparent with the increase in traffic linked to maritime shipping, traditional sea-fishing, extended aquaculture, oil and gas exploration and drilling, the development of leisure and boating activities, a wide variety of ecosystem and cultural heritage conservation initiatives, or the introduction of Marine Renewable Energies (MRE). All these different activities create a complex set of interactions that can lead to environmental risks (Halpern et al., 2008) and conflicts of use (Stelzenmüller et al., 2016), at a time when the coastal population is generally increasing (Haslett, 2000). The multiple pressures put on coastal resources and the need to harmonise sea uses require an integrated approach to planning and managing these spaces. In Europe and throughout the world, planning strategies are on the increase and becoming part of legal frameworks that guide integrated maritime policies. In July 2014, the European Parliament and Council adopted a law on Maritime Spatial Planning (MSP Directive 2014/89/EU) with the aim of contributing both to an efficient integrated management of maritime activities and the sustainable use of marine and coastal resources by creating a coherent, transparent and long-lasting decision-making framework based on conclusive data.

The importance of the concept may be acknowledged and the legal framework may be in place, but the task of applying it remains a delicate one. As the directive indicates, one of the keys to success is having an operational context with pertinent, interoperable and exploitable data. Knowing how maritime uses unfold in a spatio-temporal context, and what conflicting or synergistic interactions exist between activities, is crucial (Ehler and Douvere, 2009). However, this information is especially hard to obtain in a marine environment, where it is difficult to delineate the areas in which human activities take place (Le Tixerant et al., 2010). In fact, the marine environment can be classed as a sometimes 'vague' open space; a public space where the notion of private real estate does not exist (Queffelec and Maes, 2013); a multi-dimensional space (seabed, water column, surface, atmosphere), where traces of human activity are often ephemeral (the wake of a boat) and impacts remain invisible to the naked eye. Descriptive information on maritime activities as they take place in a spatio-temporal context has often been identified as a weak link, or the missing layer in information systems developed by maritime stakeholders (St. Martin and Hall-Arber, 2008). This information is still hard to obtain today and, consequently, is a major issue for implementing MSP.

The International Maritime Organization (IMO) has made Automatic Identification Systems (AIS) obligatory since 2002. Archived data covering almost all coastal sea and offshore areas, thanks to the development of satellite-based AIS (Loretta, 2016), has recently been made available and makes for a very useful resource in the field of operational oceanography (Koehn et al., 2013; Pelot and Plummer, 2008). In fact, analysing AIS data informs the spatial and temporal distribution of shipping (Shelmerdine, 2015) or sea-fishing (Natale et al., 2015) activities. The data from this system is increasingly used for specific fields of application, such as collision risk detection (Goerlandt and Kujala, 2011), real-time vessel trajectory monitoring (Etienne et al., 2012; Pallotta et al., 2013), assistance in managing and monitoring fishing activities (McCauley et al., 2016; Souza et al., 2016), risk assessment linked to infrastructures (submarine cables, ports, nuclear power stations on the coast, etc.), ocean current calculations (Guichoux et al., 2016), and measuring chemical pollutant (Jalkanen et al., 2014) or noise pollution (Coomber et al., 2016) emissions generated by maritime traffic. This spatio-temporal information concerning maritime activities may also be combined with socioeconomic indicators, which are very important for MSP (Stelzenmüller et al., 2016).

After recapitulating the main characteristics of AIS and the data it provides, this article proposes to evaluate how AIS is currently used in MSP at a European level, and to concisely present a series of methods and results obtained within the framework of several operational research projects set-up by the authors in different contexts. The conclusion looks at the legal questions concerning the use of AIS, discusses the use (importance - limits) of such data for MSP, and identifies research and development perspectives. 


\section{Short presentation of AIS}

AIS is now obligatory under the SOLAS convention (The International Convention for the Safety of Life at Sea, Chapter V, Regulation 19) and is being developed with the aim of making navigation safer. Under the SOLAS Convention, "AIS shall provide automatically to appropriately equipped shore stations, other ships and aircraft information, including the ship's identity, type, position, course, speed, navigational status and other safety-related information; receive automatically such information from similarly fitted ships; monitor and track ships; and exchange data with shore-based facilities". AIS shall be operated taking into account the guidelines adopted by the Organization: Guidelines for the onboard operational use of shipborne automatic identification systems (AIS) ${ }^{1}$. "Ships fitted with AIS shall maintain AIS in operation at all times except where international agreements, rules or standards provide for the protection of navigational information"2.

Based on automatic VHF radio message exchanges both vessel-to-vessel and between vessels, satellite networks and maritime surveillance centres, transmitting vessels can be georeferenced and identified in realtime. In the European Union, the obligations of the SOLAS convention have been integrated into Directive 2002/59/EC on establishing a Community vessel traffic monitoring and information system. All passenger vessels, cargo ships (merchant vessels transporting goods) of 300 gross tonnage or more and fishing vessels of more than 15 metres in length must be equipped with an AIS. Exceptions may be made under certain conditions for cargo ships of less than 500 gross tonnage used for national cabotage, and for passenger vessels of less than 15 metres in length or 300 gross tonnage used for domestic voyages. AIS provides high frequency point data comprised of three information categories (Figure 1): static information identifying the emitter vessel, dynamic information about the vessel's position and movement, and specific voyage-related information. Static and dynamic information is received every two to thirty seconds, depending on the speed and the movement of the vessel (the faster the vessel is travelling, the more frequently the AIS transmits information), and voyage-related information is received every six minutes.

\begin{tabular}{|c|c|c|}
\hline Static information & Dynamic information & Voyage related information \\
\hline $\begin{array}{c}\text { Every } 6 \text { minutes and on request by a } \\
\text { competent authority }\end{array}$ & $\begin{array}{c}\text { Dependent on speed and course } \\
\text { alteration }\end{array}$ & $\begin{array}{l}\text { Every } 6 \text { minutes, when data is } \\
\text { amended or on request }\end{array}$ \\
\hline $\begin{array}{l}\text { MMSI } \\
\text { (Maritime Mobile Service Identity) }\end{array}$ & Ship's position & Ship's draught \\
\hline Call sign and name & Position Time stamp in UTC & Hazardous cargo (type) \\
\hline IMO Number & Course over ground (COG) & $\begin{array}{l}\text { Destination } \\
\text { ETA (Estimated Time of Arrival) }\end{array}$ \\
\hline Length and beam & Speed over ground (SOG) & \\
\hline Type of ship & $\begin{array}{l}\text { Navigational status } \\
\text { (underway, at anchor, moored...) }\end{array}$ & \\
\hline Location of position fixing antenna & Rate of turn (ROT) & \\
\hline
\end{tabular}

Figure 1. Information included in AIS data (IALA, 2004)

The static information can be used to establish a more or less detailed hierarchical multi-level classification of vessels concerned by AIS into types (Figure 2). The choice of classification types can be adjusted depending on the geographical context (spatial and temporal scales, zone of study, etc.) and the aims (integrated view, risk assessment, impact assessment, etc.).

\footnotetext{
1 IMO Resolution A.917 (22) modified Automatic Identification Systems (AIS) Guidelines for the onboard operational use of shipborne Automatic Identification Systems (AIS)

${ }^{2}$ SOLAS Convention Chapter V Regulation 19 rules 2.4.5 to 2.4.7.
} 


\begin{tabular}{|c|c|}
\hline Standard AIS classification & Example of simplified AIS classification \\
\hline Cargo ship & Cargo ship \\
\hline Tanker & Tanker \\
\hline Passenger & Passenger vessels \\
\hline Fishing & Fishing vessels \\
\hline Sailing & \multirow{2}{*}{ Pleasure boats } \\
\hline Pleasure Craft & \\
\hline Engaged in military operations & Military vessels \\
\hline Search and Rescue vessel & \multirow{4}{*}{ Rescue vessels } \\
\hline Anti-pollution equipment & \\
\hline Law Enforcement & \\
\hline Medical Transport & \\
\hline Tug & \multirow{3}{*}{ Vessels used for port services } \\
\hline Port Tender & \\
\hline Pilot Vessel & \\
\hline Wing in ground (WIG) & \multirow{7}{*}{ Other types } \\
\hline Towing & \\
\hline Engaged in dredging or underwater & \\
\hline High Speed Craft (HSC) & \\
\hline Spare-Local Vessel & \\
\hline Non-combatant ship according to $R R$ & \\
\hline Other type & \\
\hline Not available & Unspecified vessels \\
\hline
\end{tabular}

Figure 2. Vessel classifications created using AIS

AIS data is accessible through several online portals such as MarineTraffic, FleetMon, AISlive or Vessel Finder, providing free-of-charge access to vessel identification and positioning in real-time the world over. These portals now also enable maritime traffic density maps to be generated (for a specific year and for either all types of vessel, or by type or size), or vessel trajectory history to be viewed, among other things. You can also submit a request for pre-processed data history for a specific zone or period. In some cases, it may be worthwhile to exploit non-anonymous raw AIS data (NMEA format) as this provides the following advantages: (1) terrestrial and satellite AIS data is acquired (optimum coverage) (2) data is received up to every two seconds (high temporal resolution) whereas the rate is lower with pre-processed data (minimum of every three minutes). However, this data then has to be extracted and pre-processed to obtain data that can be used in a GIS.

\section{Current AIS use and MSP requirements}

Systematic research was conducted on the European MSP Platform ${ }^{3}$ (Practices database), which provides a single point of access to various types of information concerning adopted or pilot plans, to evaluate current AIS use in MSP projects within Europe. The research was conducted in March 2017 and included the 24 countries cited on the platform (including Norway).

First of all, we tried to check whether an MSP plan had been officially adopted and if AIS had been used in establishing it. This was a delicate task, as the online documents did not systematically provide a detailed list of the data used. However, as Figure 3 shows, we can confirm that AIS is used in the vast majority of countries (8 out of 10 ) having adopted an official MSP plan (national or sub-national). For countries preparing an MSP plan, even if the use of AIS data is not mentioned on the documents accessed via the platform, this does not mean they are not used by current support studies for the MSP. At the same time, we listed a series of studies (Figure 3) conducted to support MSP at a regional level (e.g., BaltSeaPlan (Baltic Sea), ADRIPLAN (Adriatic Sea), PERSEUS (Black Sea), etc.) where AIS was systematically used.

\footnotetext{
${ }^{3}$ http://msp-platform.eu/
} 


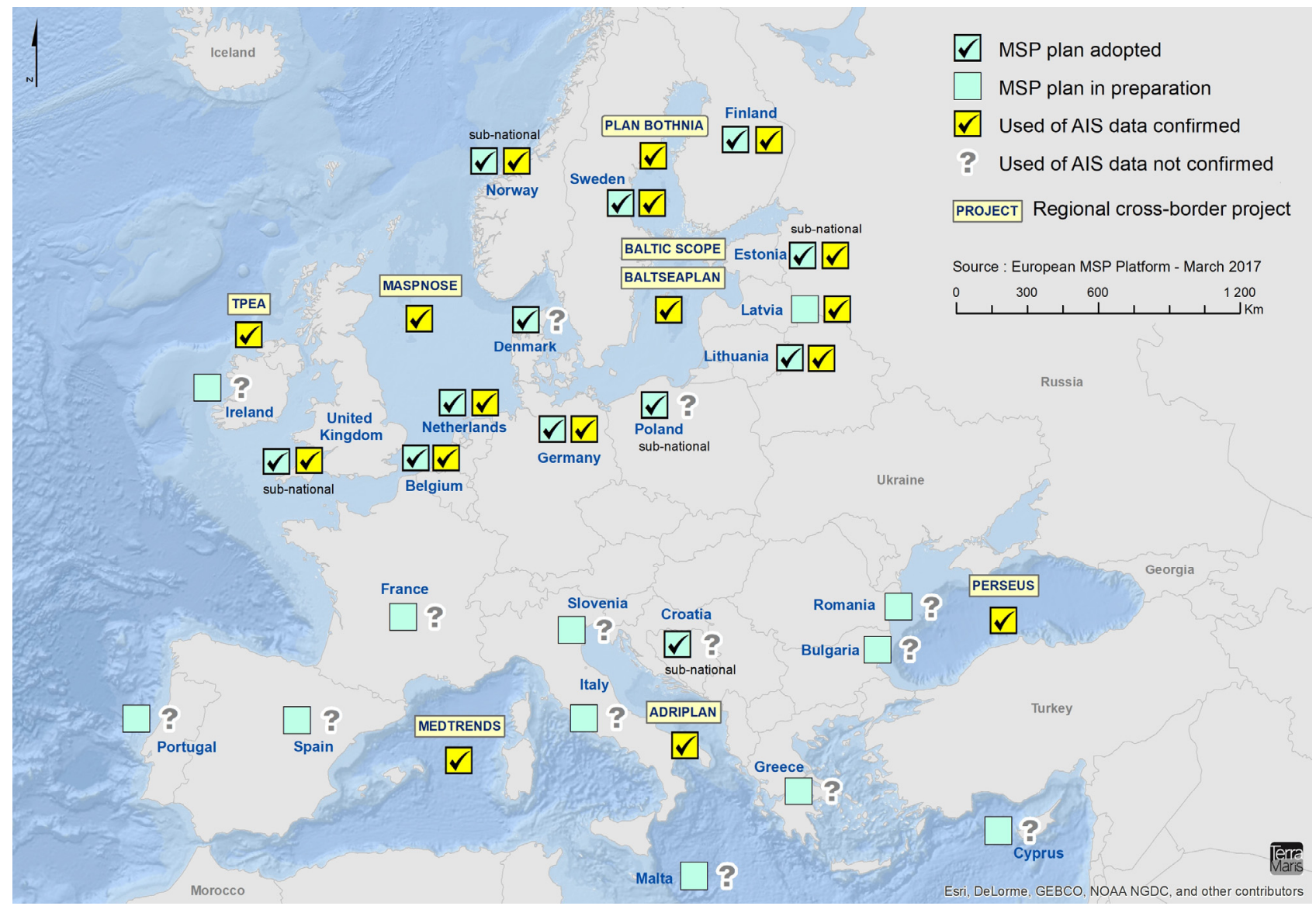

Figure 3. List of MSP plans and projects using AIS data in Europe

After producing this list, we analysed the way in which AIS was used (in full knowledge of the fact that the plans mainly present results and do not give direct information about the methodology applied). The characterisation of maritime traffic, which is essential information for planning, is approached from several different angles.

In some cases, online portals associated with MSP plans offer a real-time view of the position of vessels with the help of specialised portals like MarineTraffic (ADRIPLAN - SHAPe project in the Adriatic Sea, Estonian Pärnu Plan).

In the vast majority of plans, AIS data is presented as a density map for all types of vessel or a specific category of vessels (cargo ships, tankers, passenger ships, pleasure craft, ships transporting hazardous materials, etc.). For example, the Barents Sea MSP plan (Norway) also offers a fishing vessel density map. In the Mediterranean, the MedTrends project (not officially included in the context of an MSP plan, but stated as being associated with one) enabled a series of maritime traffic density maps based on vessel type to be produced (Figure 4). 


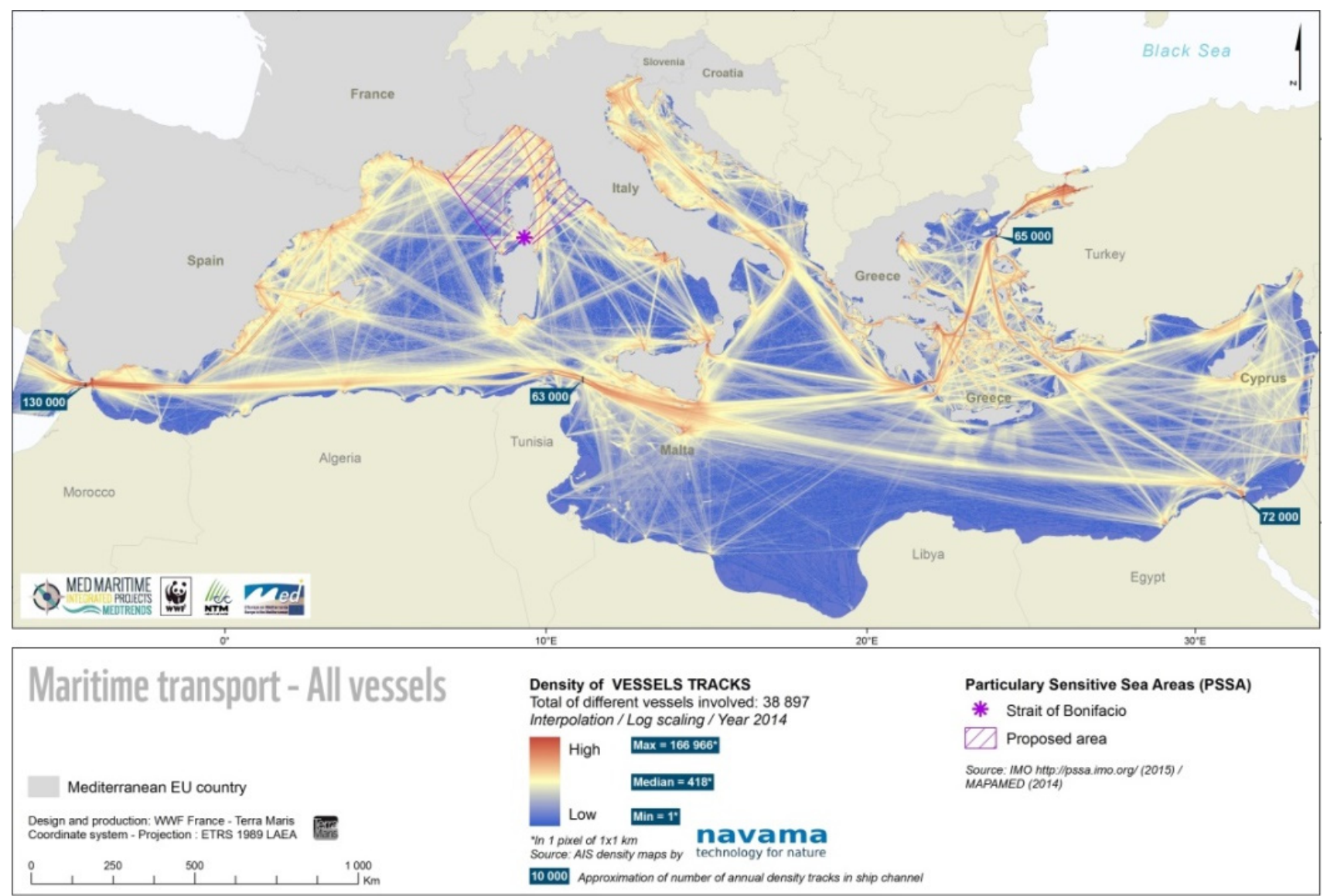

Figure 4. Example of a maritime traffic density map for the Mediterranean Sea (Piante and Ody, 2015)

The density maps produced using AIS data are sometimes available in different versions, based on the season or certain periods of the year, to explore the aspect of temporal variability in maritime traffic. In the context of the Baltic Scope (BaltSeaPlan) project, the web-based HELCOM AIS Explorer tool ${ }^{4}$ enables you to view the density of maritime traffic in the Baltic Sea by vessel type and by month over three different years, as well as according to a legend based on a logarithmic scale presenting the 'number of vessels crossing a specific zone every month'. One of the specificities of this portal is that it offers two windows displayed at the same time, making it easier to compare the different results. For the pilot MSP project in the Gulf of Bothnia, the maritime traffic density maps are presented according to the state of the pack ice (highly frozen in winter and less so in summer). One of the issues raised by these density maps is the difficulty of interpreting them, and especially of quantifying the intensity of maritime traffic. To deal with this issue, some projects (e.g., the HELCOM Map and Data Service, MedTrends) offer an estimation of the number of trajectories crossing a virtual line, often positioned in a strait or a main navigation channel, for a given period. Within the MSP project in the German Exclusive Economic Zone (EEZ), an attempt is made to quantify intensity based on AIS data and according to the shipping lanes and the direction of traffic (going East or West). The question often raised is whether quantification refers to calculating the number of vessel passages (estimated according to the number of trajectories), which serves to highlight the navigation flows, or calculating the number of different boats (MMSI number), which is more adapted to exploring the diversity of vessels travelling in/through the zone. One of the main reasons for exploiting AIS data is to determine the main shipping lanes or channels, also referred to as 'motorways of the sea', 'zones/routes with a high density of maritime traffic', 'main shipping routes/lanes', etc. These analyses aim to obtain a spatially-oriented and synthetic view of maritime traffic, and establish priority zones for shipping. It is also important to note that even if AIS data is mainly used and presented at a regional level (e.g., BalteSeaPlan, ADRIPLAN, MSP for the Barents Sea, etc.), it can also be used at a local level (e.g., Sound of Mull Marine Spatial Plan (Scotland), Dorset C-SCOPE project (England)). 
As indicated in (Nicolas et al., 2016), this research on projects and studies connected with MSP at a European level confirms that AIS is tending to become an essential factor for this type of policy.

In France, a series of semi-structured interviews conducted with several maritime stakeholders (government services, professional sea-fishing organisations, NGOs, industrial operators) within the framework of a research project supported by the Fondation de France (Le Guyader et al., 2016) confirmed the importance of AIS, in accordance with (Wichorowski et al., 2011; Nicolas et al., 2016), to:

- produce adapted and optimised maritime traffic information for assisting with maritime spatial planning (relevant density maps, homogeneous maritime routes (lanes), a hierarchical network of maritime routes (primary, secondary, tertiary, etc.), spatially represented vessel flows, etc.). It became clear that there is a need for more detailed information on small-scale fishing activities and leisure activities (not currently legally concerned by AIS). Some of the actors interviewed underlined the importance of more dynamic display modes that reflect reality (especially the inclusion of a time factor), as static map displays can sometimes provide a view that is biased towards the impression that marine space is systematically overcrowded;

- access relevant information on sea fishing by testing methodologies on different crafts and on different scales;

- highlight the spatio-temporal interactions between activities by integrating a compatibility index to identify potential conflicts of use, and by combining AIS with data from other sources (e.g., regulated zones, data issued from interviews, field observation data, etc.);

- have access to information on the pressures and cumulated impacts by combining AIS data with environmental data;

- have a projected outlook on maritime traffic enabling future navigation lanes to be identified according to an increase in traffic, or following the development of new use for a space (e.g., MRE).

\section{Moving towards producing MSP-compatible information drawn from AIS}

Between the moment an AIS signal is emitted and the moment it is used in MSP, pre-processing operations (Figure 5) are essential and different spatio-temporal analyses can be envisaged to obtain relevant, new and usable information (Le Guyader et al., 2012; Nicolas et al., 2016).

When raw data is acquired (NMEA format), before it can be used in a GIS, a first processing stage is required consisting of extracting and decoding AIS frames concerning the study site area, and then importing and structuring data in a database. After that, a layer of points representing the gathered AIS positions in the zone of study is generated. At this pre-processing stage, data is filtered for anomalies, which are then corrected (deletion of onshore-referenced positions, duplicate signals, incorrectly entered MMSIs, etc.). The third stage generally consists of reconstructing the ships trajectories as polylines connecting successive AIS positions (points) and containing the initial AIS attributes. Additional data can be linked to these lines, for example, the type of cargo or the main type of fishing gear used. 


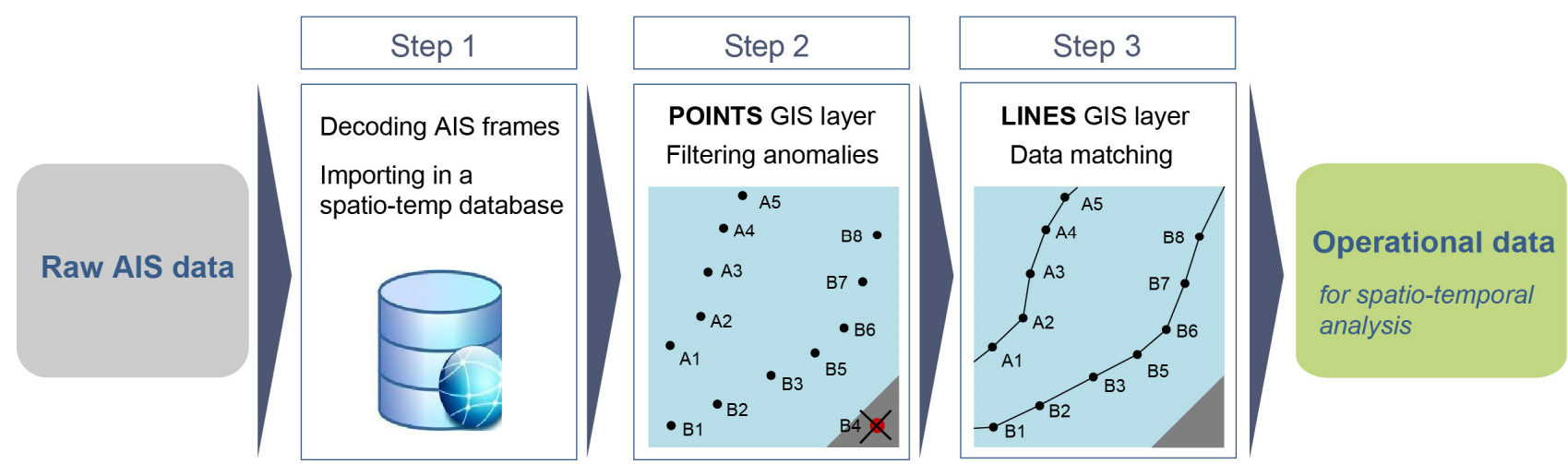

Figure 5. Main pre-processing stages for raw AIS data

For very high traffic zones and long periods covering several months or years, these information layers provide very few usable details visually as there are too many entities, leading to saturation of the display (Figure 6).

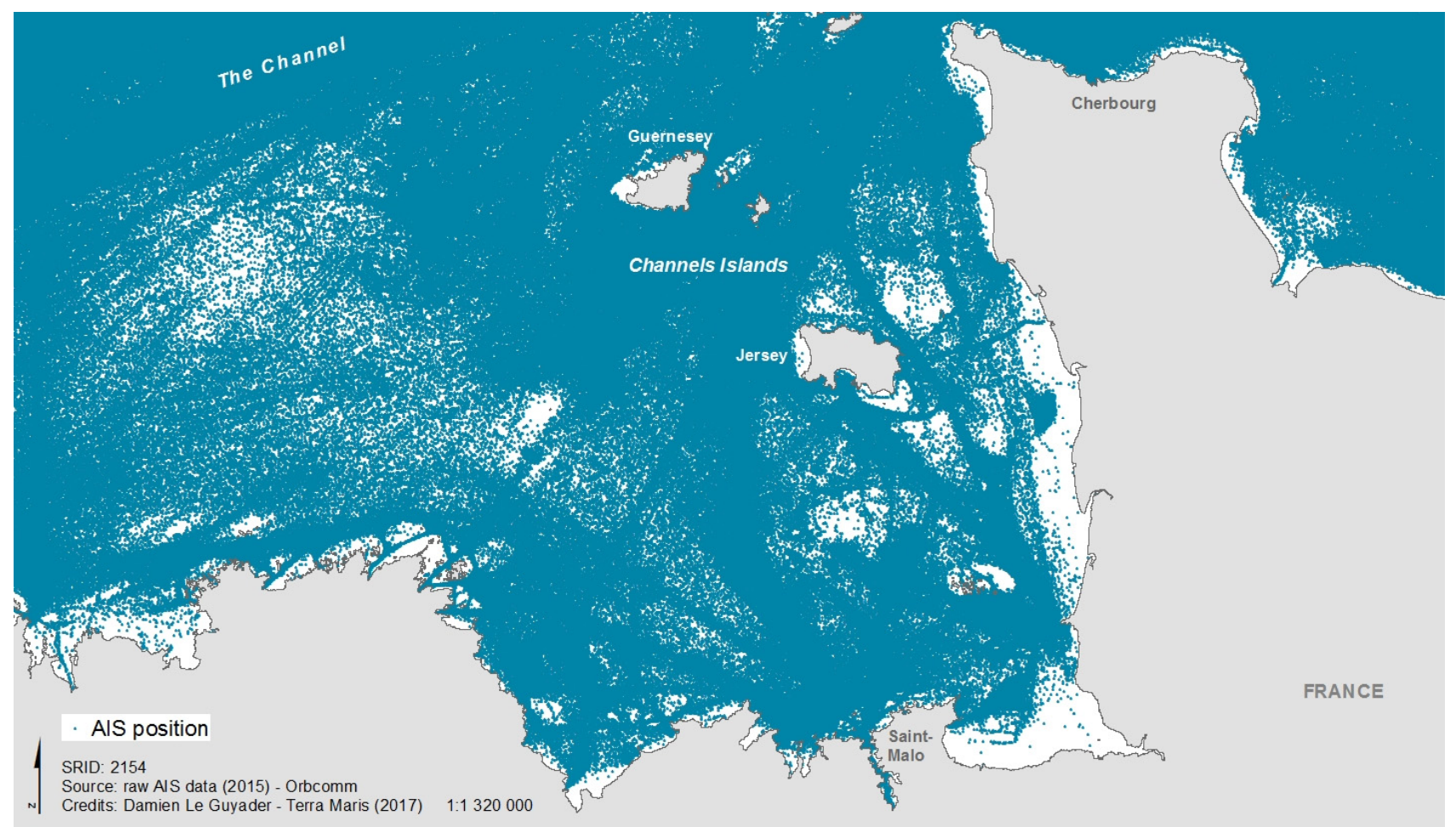

Figure 6. Display of terrestrial and satellite AIS (all vessels included) positions (points) collected over a specific region

A more in-depth spatio-temporal data analysis is essential to obtain sufficiently succinct information that can be used in an operational management context. 


\subsection{Making it easier to interpret maritime traffic density maps}

Although density maps produced in the context of MSP projects are visually effective, the details are often difficult to interpret. Even with a legend (not always provided), a non-specialist would find it quite challenging to decipher such a map. As a result, it may be difficult to evaluate the number of vessels having travelled in or through a specific zone for a given period. The densities measured generally consist of the relation between the volume (number of positions or trajectories) or lengths (of trajectories) and a surface unit, but these items of information are not always mentioned explicitly. Furthermore, results are often presented on a yearly basis, which implies including a very large number of entities and using mainly logarithmic-type classifications (a very broad range of values) that can lead to errors of interpretation for the layperson. To make this mapped information more understandable, we suggest using a mode for displaying the density of maritime traffic that shows the sum of daily ships trajectories per surface unit (pixel) for a whole year, for example (Figure 7). The number of ships trajectories can also be assimilate with the number of ships crossing the pixel.

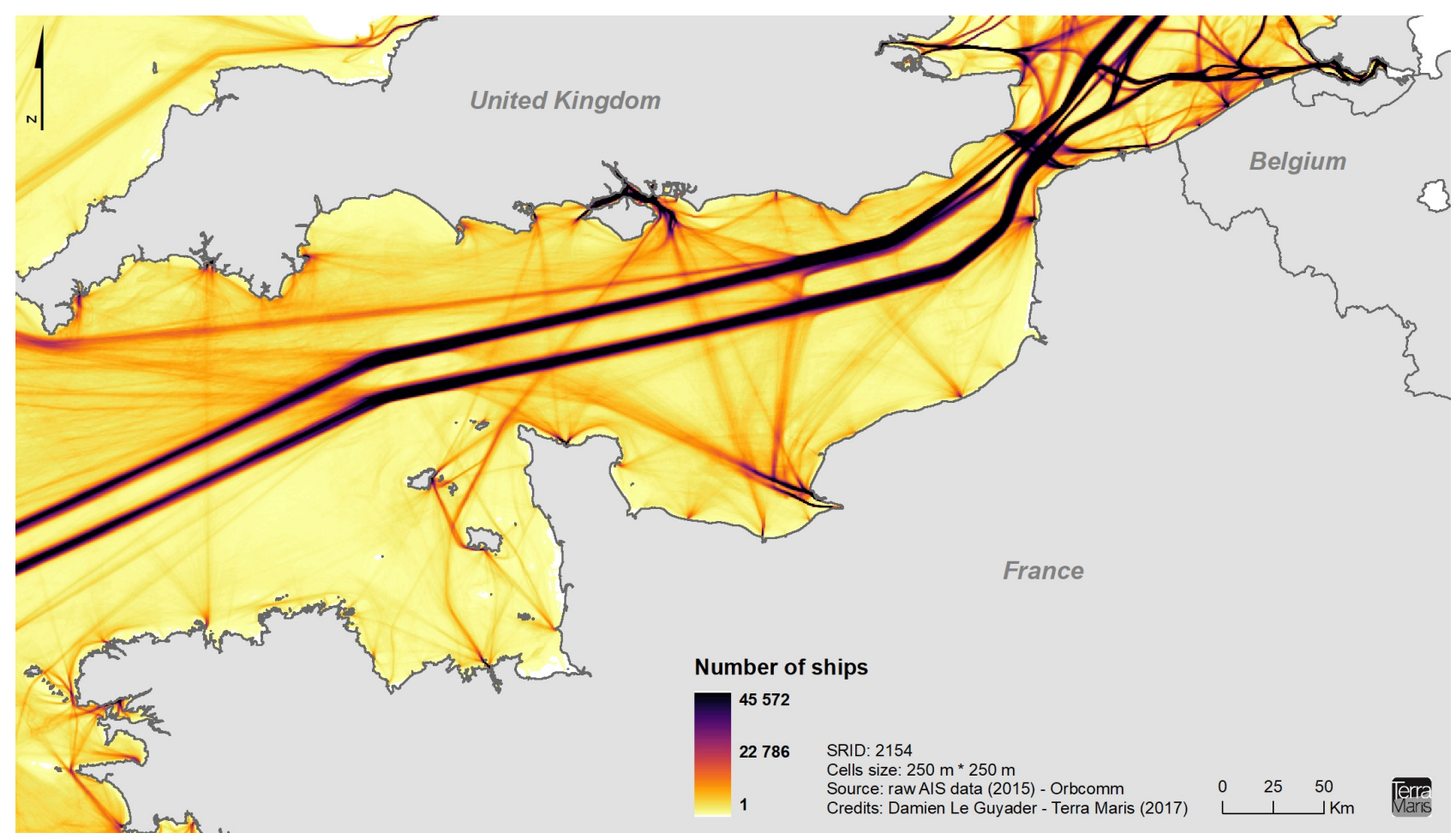

Figure 7. Example of a map showing the intensity of maritime traffic according to the number of trajectories per pixel (for year 2015 - all vessel types) 


\subsection{Identifying the main shipping lanes}

Most MSP projects endeavour to highlight the main shipping lanes in the zone of study (motorways of the sea, zones with a high density of maritime traffic, main shipping routes/lanes, main channels, etc.) with the aim of providing a succinct view of maritime traffic, and of possibly establishing the boundaries of highpriority shipping zones. It turns out that the MSP project documents we studied provide very little information on methodologies for producing shipping lanes. Two methods were tested in the Bay of Brest (Le Guyader et al., 2012): an analytical approach based on density and only the most significant classes of vessel (for example, classes that represented about $90 \%$ of all traffic density), and an approach based on kernel density. The approach based on kernel density seems to be more relevant as it provides a clearer and thus more succinct spatial view. In addition, it does not involve non-automated calculations, which significantly reduces processing times. This method gives satisfactory results, especially when the data set initially contains homogeneous groups of trajectories (departure and arrival points are identical and the spatial footprint is not too spread out). The first tests were carried out using more complex data sets over larger geographical areas (Iroise Sea) with the aim of optimising the method (Figure 8).

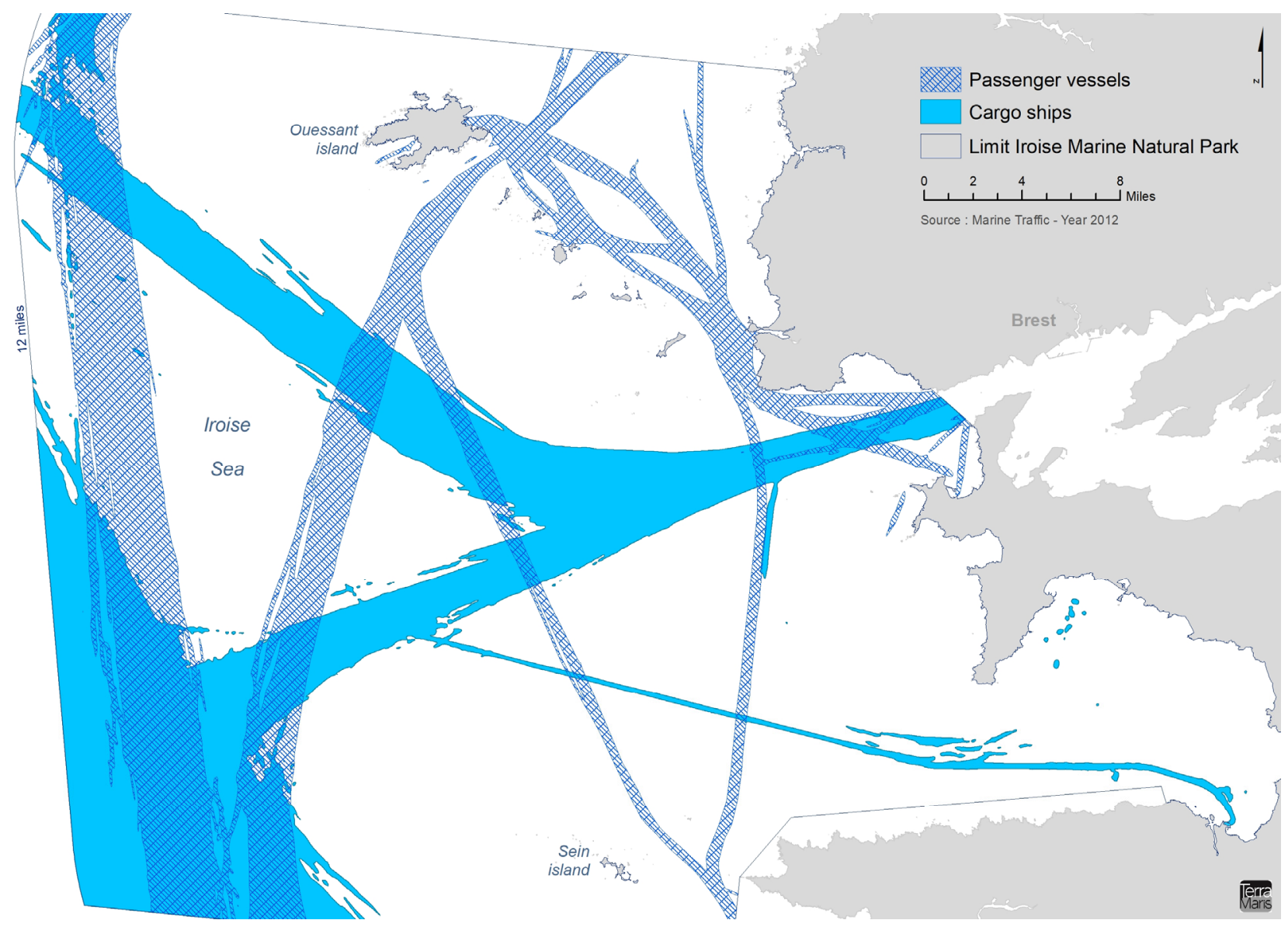

Figure 8. AIS data used to highlight the shipping lanes in the Iroise Sea (France) 


\subsection{Highlighting a hierarchical network of maritime routes}

Several MSP projects put forward the concept of 'motorways of the sea', identified by creating a hierarchy of maritime routes (primary, secondary, tertiary, etc. network). The purpose is to obtain a succinct spatial view of the main routes and the associated traffic intensity. R\&D work on developing a specific algorithm is currently underway to identify a hierarchical network of maritime routes using trajectory density (Figure 7). Generally speaking, the method used to define this hierarchical spatial network relies on automatically identifying the nodes (prominent ports and points of interest) and the segments or connections defined as the least cost pathways between nodes. Spatial constraint is characterised by a composite friction layer that is dependent on the distribution of trajectory density as well as Strahler's hierarchical networks (Strahler, 1957). The first tests are currently underway in the Channel (Figure 9) and can be viewed via an online map application (link).

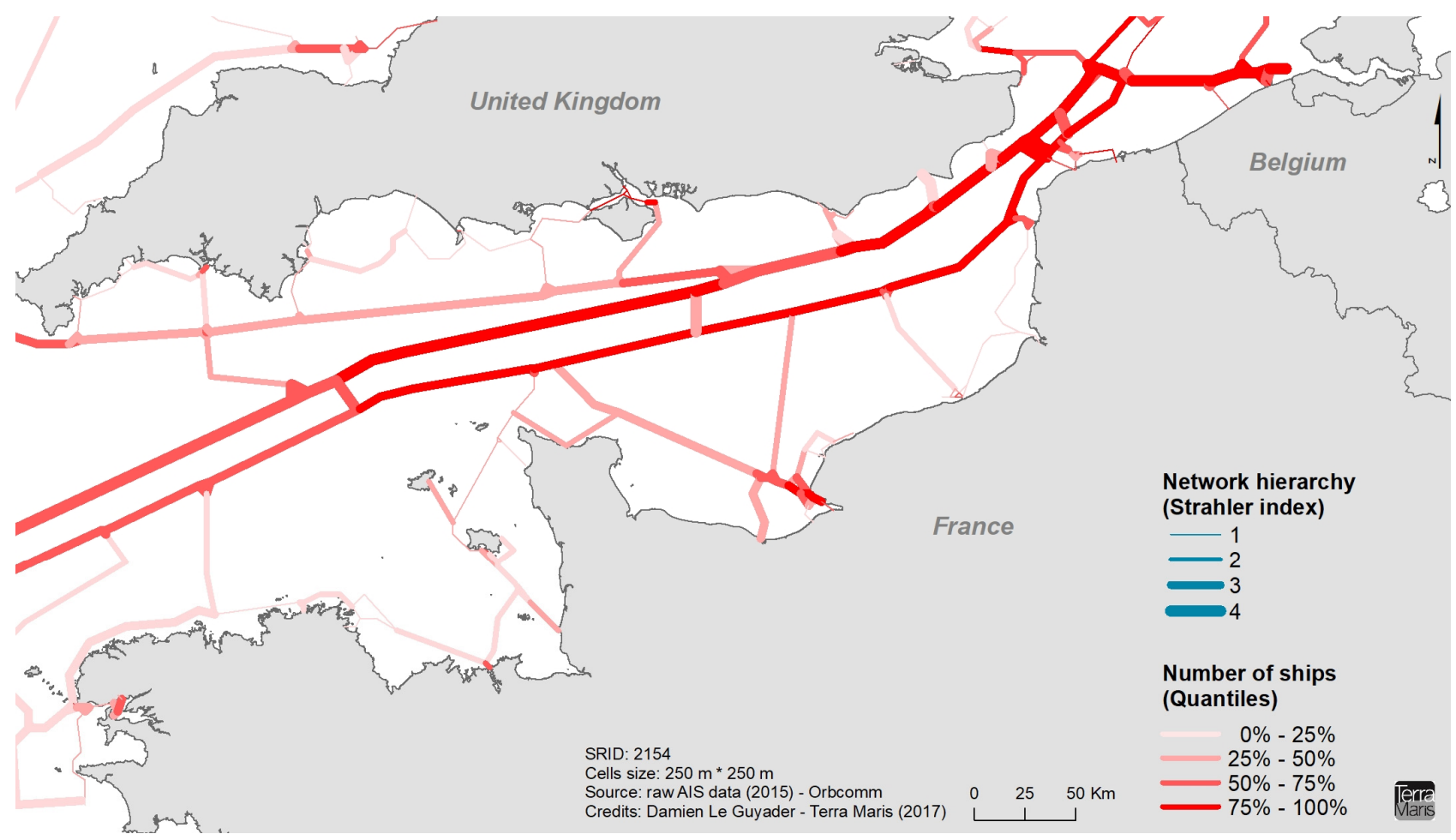

Figure 9. Highlighting a hierarchical spatial network of maritime routes in the Channel 


\subsection{Identifying alleged fishing zones}

A more detailed picture of the spatio-temporal distribution of sea fishing activities is essential within the framework of an MSP process. In this domain, the reference data comes from VMS (Vessel Monitoring Systems) rather than AIS (Jennings and Lee, 2012; Nicolas et al., 2016). In Europe, this vessel monitoring system based on satellites was simultaneously introduced with AIS (Leboeuf and Proutière-Maulion, 2013), in the 2000s by the European Union to control commercial fishing (Council Regulation (EC) no. 686/97 dated 14 April 1997 amending Regulation (EEC) no. 2847/93 establishing a control system applicable to the common fisheries policy). Since 1 January 2012, VMS has been obligatory for all fishing boats over $12 \mathrm{~m}$ in length, unless exempted (Council Regulation (EC) no. 1224/2009 establishing a Union control system for ensuring compliance with the rules of the common fisheries policy). VMS provides reports on the position of the vessel (georeferencing) at regular time intervals ranging from one to two hours (Hintzen et al., 2012). VMS data is generally exploited at a spatial resolution of 1 to $10 \mathrm{~km}$ due to transmission being less frequent than with AIS. Furthermore, for confidentiality reasons, access to raw VMS data is often highly restricted (Lee et al., 2010). Combined with VMS data, the relatively easy-to-access archived AIS data has just recently created new research opportunities for spatialising fishing activities on different scales (McCauley et al., 2016; Natale et al., 2015; Souza et al., 2016; Vespe et al., 2016). Irrespective of the identification system (AIS or VMS), fishing activities are characterised by:

1. assigning a métier (fishing gear, target species) to each vessel for each fishing period. AIS data does not include such information. A type of fishing gear or even métier can be assigned to each vessel for each fishing period by crossing AIS data and logbooks;

2. identifying the position of vessels when fishing. Insofar as georeferencing data is not crossed with explicit information concerning activities undertaken while the vessel is out at sea, distinguishing between fishing (the fishing gear is in use) and non-fishing (travel, mooring, drifting, etc.) positions becomes vital. To do this, a speed filter is generally applied to vessels (Mills et al., 2007);

3. identifying fishing zones. In most studies, fishing zones are defined as the maximum area occupied by the positions of vessels when they are assumed to be fishing;

4. calculating fishing intensity and effort. Effort is defined as a combination of fishing capacity, which depends on the characteristics of the vessel (tonnage, horsepower) and the fishing gear, and the estimated fishing time in a given zone (Campbell et al., 2014) (Figure 10).
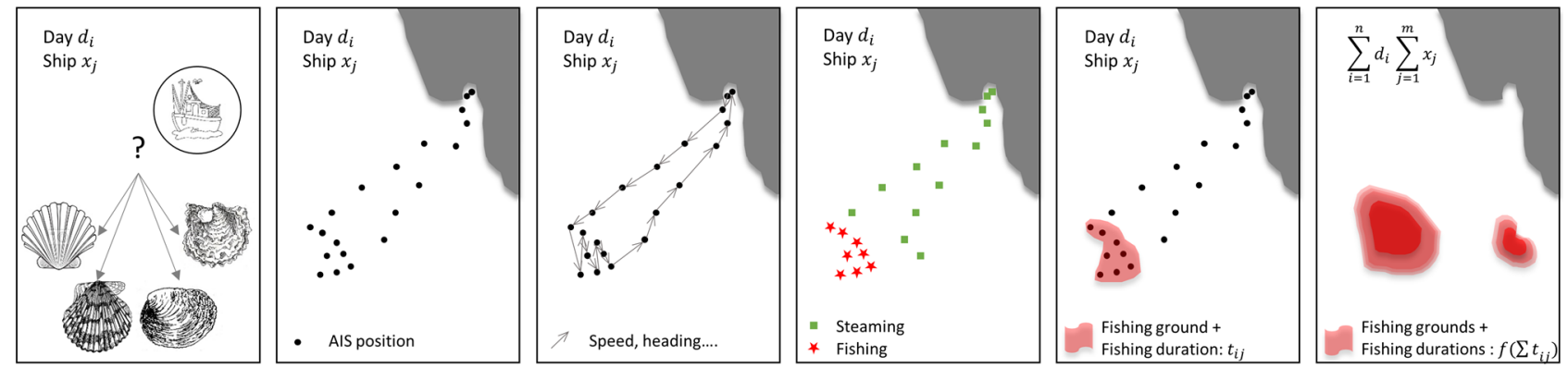

Figure 10. Illustration of the method for identifying fishing zones based on AIS/VMS data (Le Guyader et al., 2016)

The methodology, detailed in (Le Guyader et al., 2017) was tested in the Bay of Brest (France) using AIS data for shellfish dredging activities. The studies were carried out with the Comité départemental des pêches maritimes - CDPMEM29 (district-level committee on sea fishing), who wanted a more detailed view of dredging activities to be able to monitor its fleets, contribute to analysing potential impacts on the natural environments, and better share the geographical area they operate in with other users (Figure 11 and Figure 12). The method was evaluated in the field (by on-board observers equipped with a GPS) and by drawing on the knowledge of the fishers. 


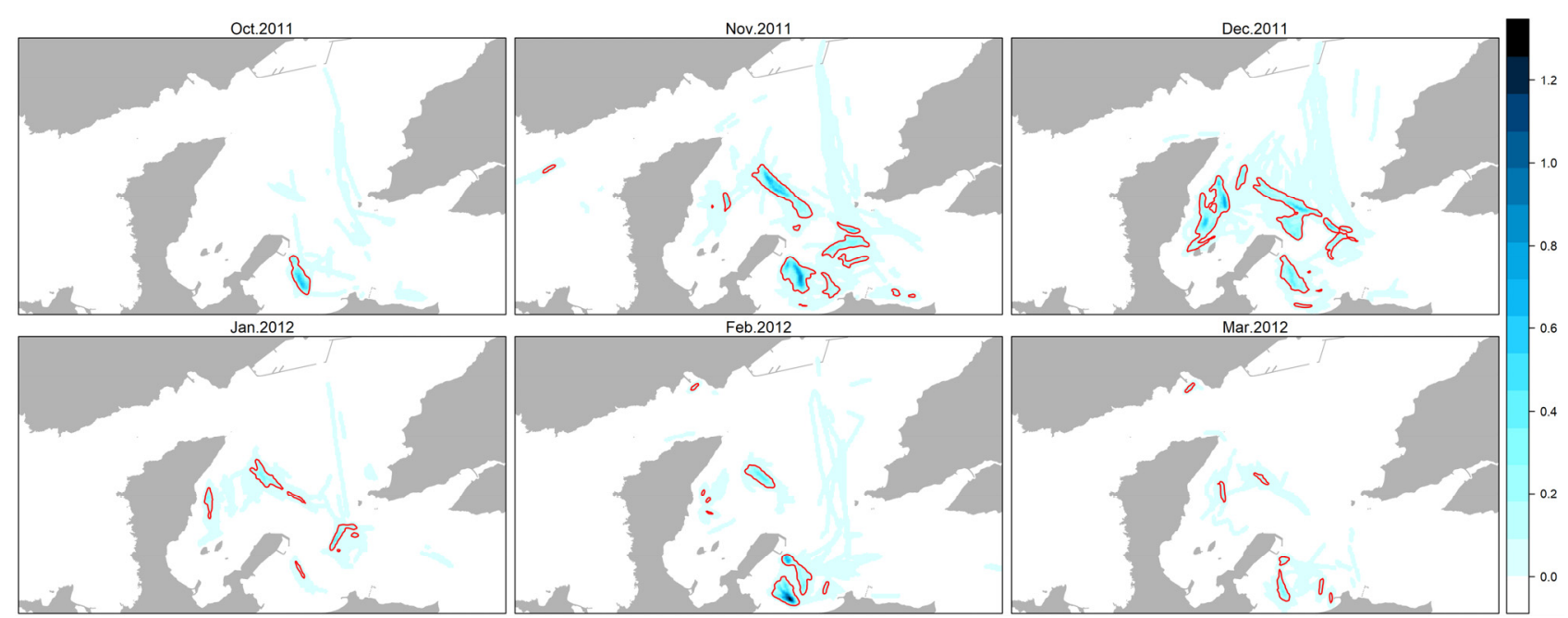

Figure 11. Monthly distribution of Kernel density for daily fishing segments and fishing zones identified for the scallop dredging - 0.95 percentile (Le Guyader et al., 2016)

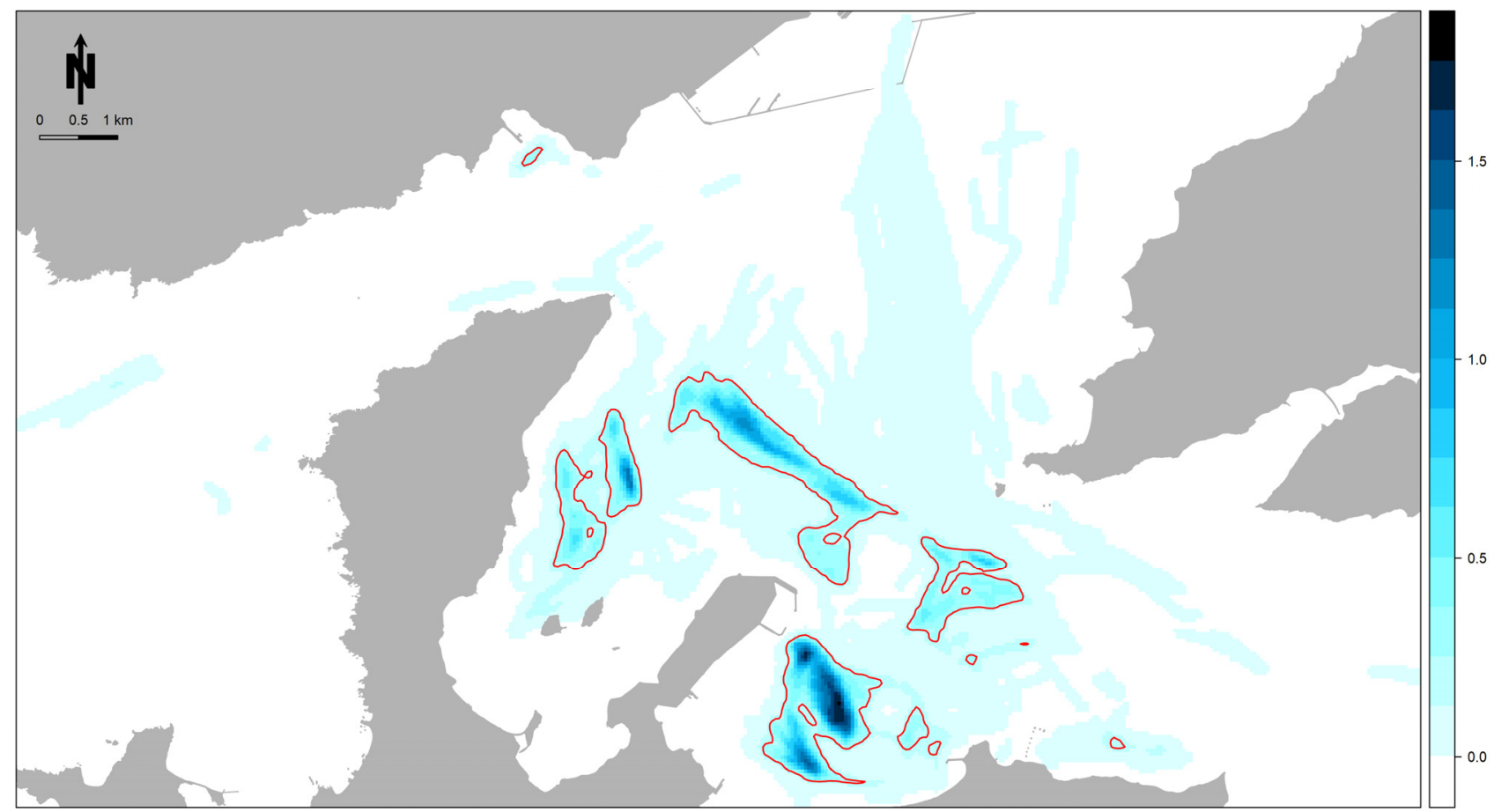

Figure 12. Annual distribution of Kernel density for daily fishing segments and fishing zones identified for the scallop dredging - 0.95 percentile (Le Guyader et al., 2016)

These studies showed the potential of AIS both as a complementary approach (Russo et al., 2016) to other sources of information usually used (VMS, survey data), and in providing detailed knowledge about coastal fishing practices on a local scale.

\subsection{Spatio-temporal interactions between uses}

One of the main objectives of MSP is to assist in analysing the interactions between activities to avoid potential conflicts (Ehler and Douvere, 2009). Combined with other data, AIS can contribute to exposing several types of interaction.

\section{Interactions between the activities observed and regulated zones}

The requirements identified by the managers of marine spaces (Le Guyader et al., 2016) included an evaluation, based on objective data, of the compatibility between the activities observed and current regulatory measures. It was possible to test this type of analysis locally thanks to AIS data. For example, Figure 13 compares the spread of positions for cargoes and tankers declared as 'being at anchor' and whose speed was less than one knot with regulated anchorage areas. Figure 14 compares the shipping 
lanes actually used by tankers (generated using AIS data over a one year period) with regulated channels for accessing the port. This type of illustration is useful for people managing maritime space as they can adapt regulatory measures to practices, or better deploy monitoring and control measures.

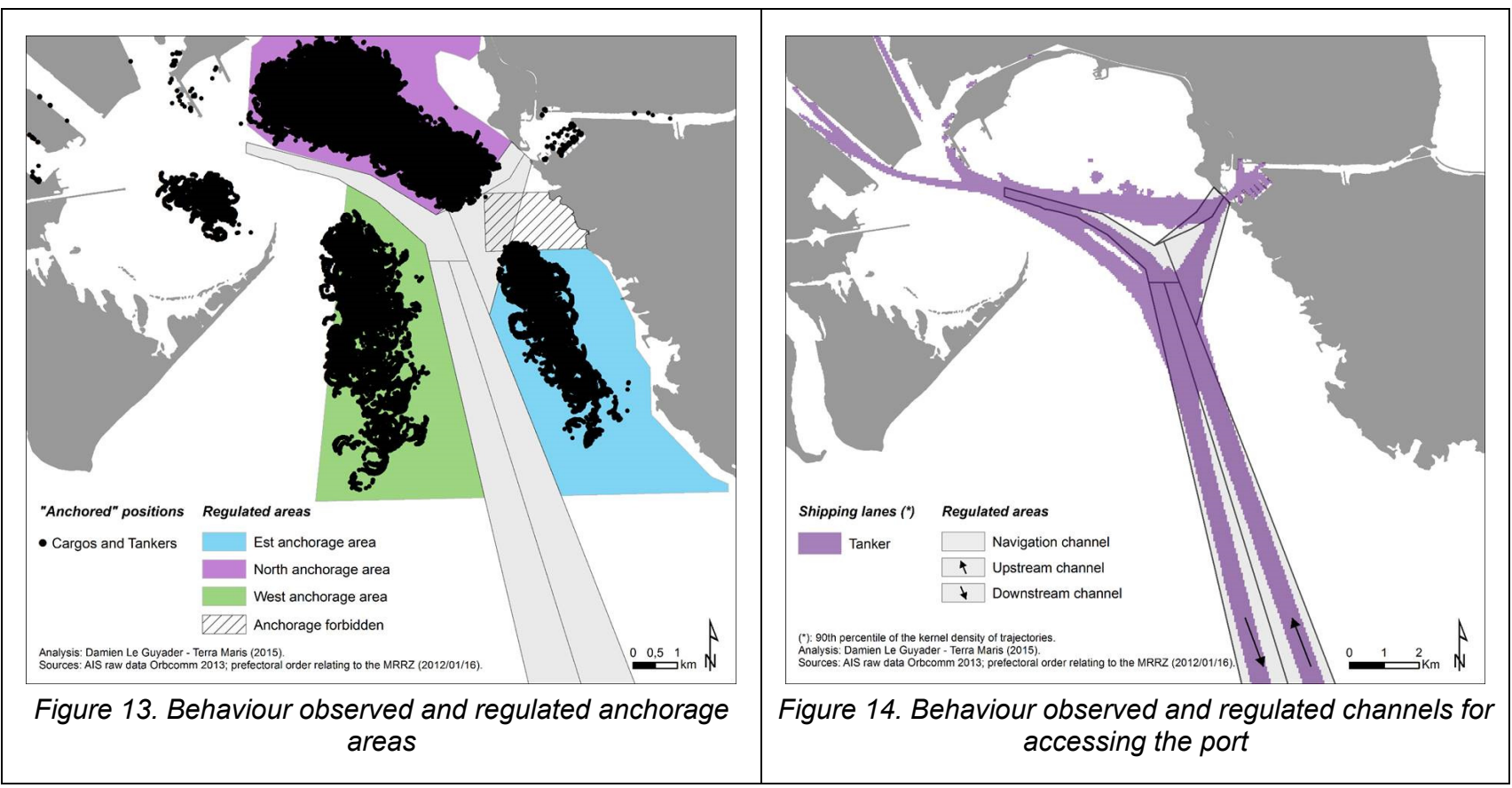

\section{Interactions between maritime traffic and sea- or coastal-based infrastructures}

As a risk avoidance strategy, it may be useful to identify the proximity of vessels passing near an abovewater sea- or coastal-based infrastructure. This exercise was carried out using AIS data to estimate the risk regarding sensitive installations on the coast (e.g., nuclear power stations, gas and oil storage facilities, etc.) with ships transporting hazardous materials passing in the vicinity.

Concerning underwater infrastructures, AIS data can also provide precious information for risk assessments linked to maritime navigation. For example, exploiting AIS data for a submarine cable installation project can allow risks linked to vessel anchorage to be analysed, and more specifically, the risk of anchor dragging in bad weather conditions. Once the weight of anchors have been estimated, specific spatial analysis methods need to be developed to identify the potential location of anchors and the estimated drag distances. AIS data includes information on the location of the AIS emitter on the vessel and the vessel's course every time its position is emitted. Using this information, the spatial footprint of the vessel and its direction can be calculated for each AIS position of vessels declared as 'being at anchor'. The potential location of the anchor for each AIS position is estimated using the length of the chain. As the direction of the vessel is known at any moment, a circle with the radius equal to the length of the chain is calculated based on the position of the vessel. The zone corresponding to the potential anchor location is calculated for each successive position over time. These zones are saved on a daily basis per vessel and their total is calculated according to a specific spatial resolution (Figure 15). In light of the gyratory movement of the vessel over time (t1, t2, t3) (Figure 16), the anchor drag distance cannot be estimated using the distance calculated between the successive positions of the prow, nor using the distance between the AIS emitter points, but rather by evaluating the translation of the centre of gyration (anchor position). Consequently, the position of the centre of gyration (g) must be calculated by intersecting the directions of a vessel over a single day. The median distance between the vessel's centre of gyration and the prow is then estimated (D). Supposing that (D) is a constant length, the centre of gyration positions are calculated for each vessel position over time (g1, g2, g3, g4). The drag distance is thus estimated by calculating the distance between the centre of gyration positions (Figure 16). 


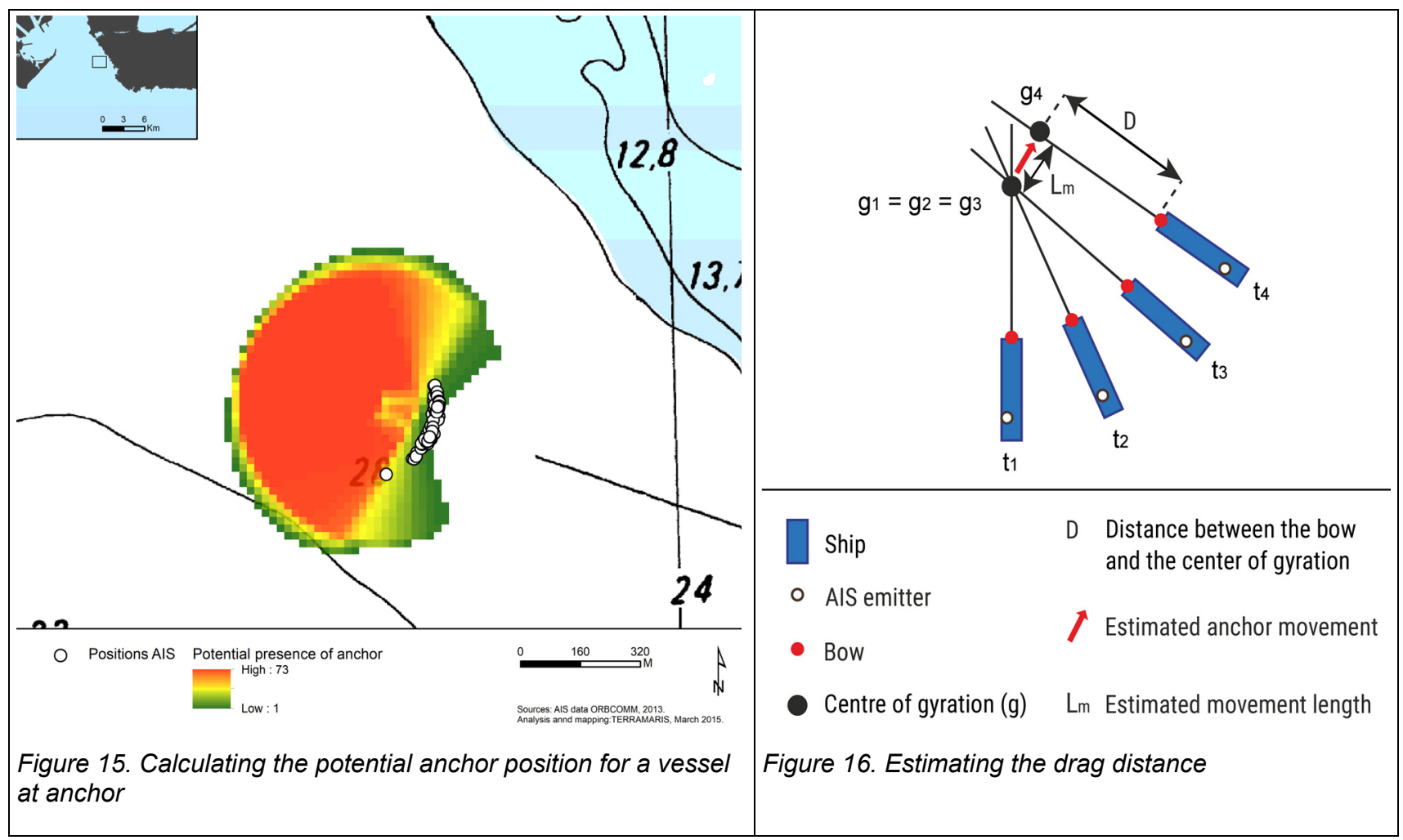

Even though the results were obtained in the context of an operational study, they still have to be viewed with caution as the exact position of the vessel based on AIS data remains uncertain (approximately $10 \mathrm{~m}$, give or take), as does the course given by the AIS (give or take $0.1^{\circ}$ with regards to True North). Nevertheless, this case study illustrates how AIS data can be exploited on a more detailed level for precise and specific planning issues.

\section{Spatio-temporal interactions between different uses of maritime space}

Highlighting the spatio-temporal interactions between the different uses made of maritime space implies combining AIS data with other types of data (regulatory data, data from stakeholders, observation data, statistics, etc.) into a spatio-temporal database that can be exploited by a GIS. One of the main advantages of AIS data is that it inherently offers both a spatial and a temporal dimension. As a result, a database that includes AIS data can be used to describe day-to-day human activity in the studied zone over a year by identifying the activities likely to take place on a given day during the year, spatialising the zones where such activities take place, and identifying the density of vessels or other supporting equipment associated with activity zones, by activity.

This database can also be used to identify, qualify and quantify the potential interactions between the different maritime activities noted. The potential interactions between different sea-related activities are usually displayed by spatially superposing zones where each activity takes place (Maes et al., 2005; Brody et al., 2006; Gimpel et al., 2013); spatial interactions are characterised either by a quantity indicator (the total number of activities), or by a quality indicator (presence/absence of conflicts of interest, or seriousness of potential conflicts). However, not taking the dynamic temporal dimension into account is especially problematic at sea as some activities can take place in the same location, but not at the same time. This justifies distinguishing between spatial intersections and spatio-temporal interactions. In the Bay of Brest, a spatio-temporal database was used (Le Guyader, 2012; Gourmelon et al., 2013) to identify, spatialise and quantify the spatio-temporal interactions between activities on a daily basis for a whole year (Figure 17). The added value of taking the temporal dimension into account was evaluated by comparing it to a purely spatial approach to highlighting potential interactions between sea-based activities. It was shown in the Bay of Brest that including the dynamic spatio-temporal dimension of activities provided information that was significantly different by $70 \%$ compared with a spatial-only approach. 


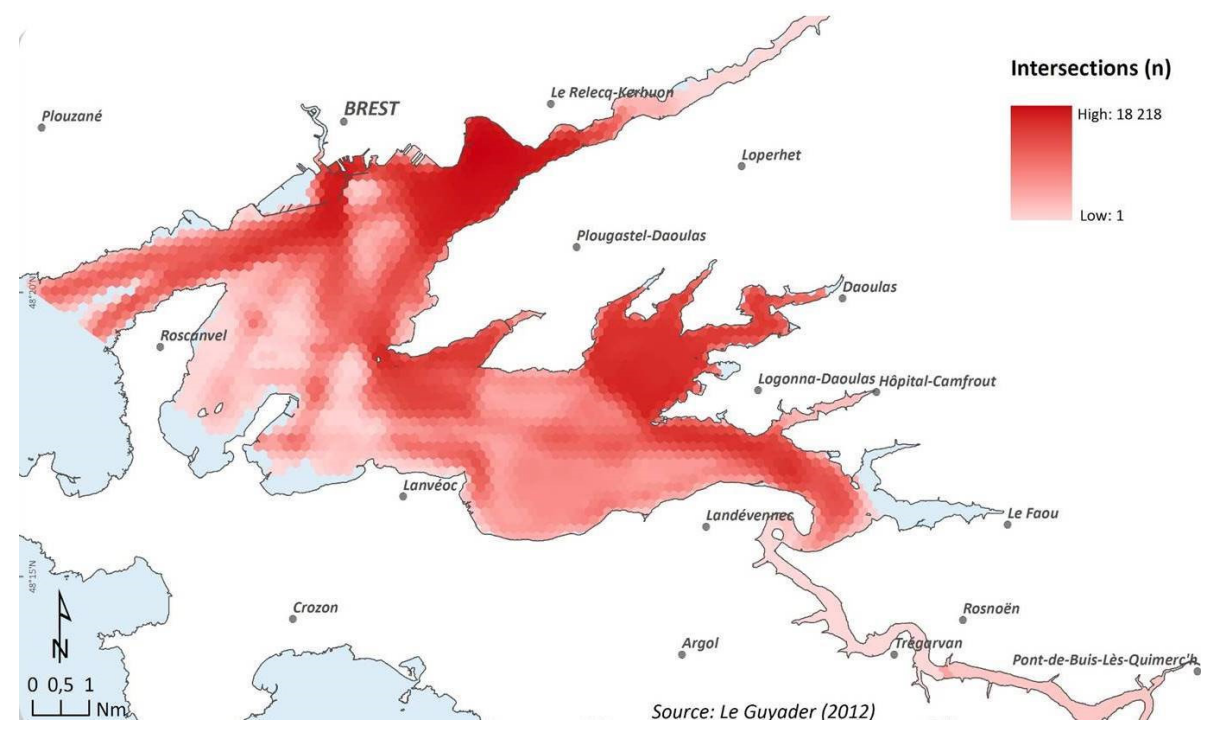

Figure 17. Spatio-temporal interactions in the Bay of Brest for 2009 (Le Guyader, 2012)

A spatio-temporal interaction hierarchy between activities can be established based on this type of result. In the Bay of Brest in 2009, there is strong interaction between some activities (e.g., passenger transport and supervised nautical activities) and less between others (e.g., supervised diving activities do not take place in the same zones as dredging or longline sea bass fishing). To identify which activities may potentially come into negative interaction or conflict, the spatio-temporal interactions between activities need to be weighed up using a qualitative compatibility index that can be determined using literature or user surveys. An sufficient level of spatio-temporal interaction combined with evidence of antagonism between the different activities concerned serve to determine whether there is a risk of negative interaction and ensuing potential conflict. This type of result can be presented in a standard way as a matrix, but also as a graph, to obtain a result that is more visually explicit (Figure 18).

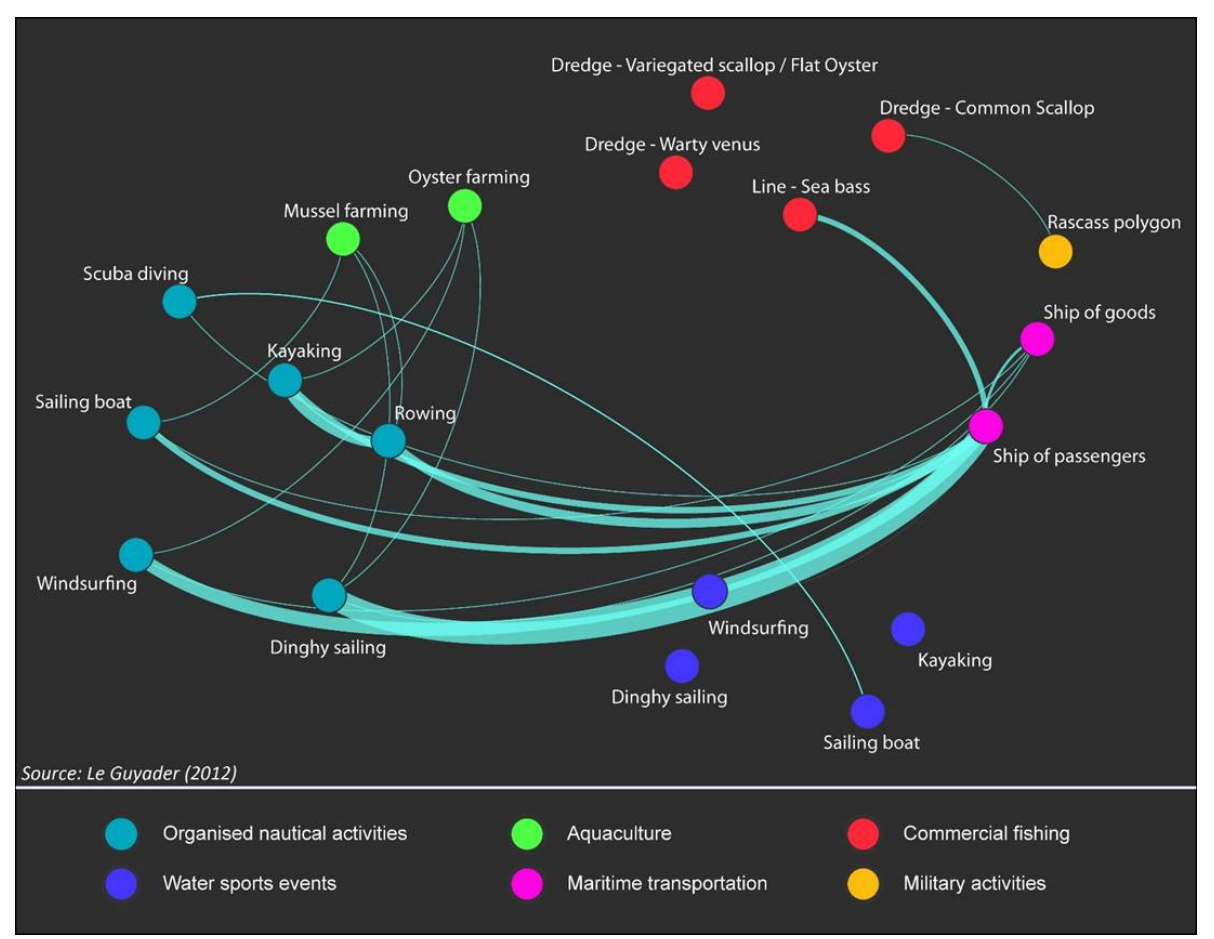

Figure 18. Overall spatio-temporal interactions with evidence of 'stakeholder reported' antagonism between activities in the Bay of Brest in 2009 (Gourmelon et al., 2013) 


\section{Conclusion}

A review of MSP plans in Europe show that AIS contributes to implementing an integrated maritime policy. Its main advantage lies in the role it plays in highlighting maritime traffic, with the possibility of doing so by vessel type and time of year. It enables position or trajectory density maps to be established, on condition that special care is taken to make them easy to interpret correctly by non-specialists. Maps can show the main shipping lanes in conjunction with quantitative data to highlight the main navigation flows. A hierarchical network of maritime routes can also be highlighted. Even if AIS is not regarded as the reference data source in this field and does not concern all vessels, this type of data can potentially be used to describe sea-fishing activities. As satellite AIS develops, one of the major benefits is potentially having access to this type of data on a worldwide scale. Through the examples given, we have shown that this type of data can be exploited both at a global (e.g., Mediterranean basin) and local level for specific fields of application (e.g., evaluating anchor dragging risks with a view to installing submarine cables). As it inherently includes a time factor, it provides a dynamic view of activities taking place, in keeping with the reality of this open and shared space. Combined with other spatialised information (e.g., regulations, surveys, observations, etc.), AIS can also contribute to qualifying and quantifying spatio-temporal interactions between activities over different time periods. This assists in assessing the risks of use conflicts in a marine space. Lastly, AIS can also be crossed with other data (vessel characteristics, cargo type, type of fishing gear, etc.) to produce new and richer spatialised indicators. Integrating AIS data into maritime space information systems is an advantage and clearly provides further means for delivering objective and relevant information to promote dialogue within a marine spatial planning context. This said, using AIS data in an MSP context is not all plain sailing.

From a technical point of view, the use of raw data in particular, requires specialised knowledge and IT hardware and software that is suitable for handling a high volume of source data, especially when working on large-scale areas with a very high level of traffic. Therefore, the right skills and tools are essential to optimising and automatically processing some tasks. One of the challenges is to be able to produce the same type of information in a multi-scale context, and especially, obtain a result that is relevant for a whole range of different spatial scales (from local to regional).

In several sectors, such as fishing, not all vessels have AIS, despite a purported increase in the amount of AIS equipment on vessels the world over (McCauley et al., 2016). In some countries (e.g., Mauritius or Ecuador), AIS is now obligatory for all vessels, whereas in others, all vessels are exempt (e.g., Canada). In Europe, $75 \%$ of European fishing vessels are fitted with AIS (Natale et al., 2015), but it is only obligatory for vessels over $15 \mathrm{~m}$ in length. Only in exceptional cases does AIS cover small-scale coastal fishing, despite the fact that this type of activity is a major stake in planning strategies. In addition, AIS data does not include the precise métier (type of gear used, targeted species) of each vessel during a fishing trip. Consequently, crossing it with other data (logbooks) is essential. Identifying fishing zones using AIS data (distinction between assumed fishing and transit positions) requires implementing complex and variable methodologies depending on the gear used. Our experience shows that this is still a very sensitive subject for professionals, but inevitably, using this data requires working closely with them.

Most leisure boats, especially small leisure craft and leisure fishing boats, are not equipped with AIS. As a result, AIS cannot be used to describe this type of activity.

In addition to these technical constraints, there is a rather unclear legal framework that may well develop and lead to restricted access to this type of data. According to Directive 2002/59/EC, AIS data is generally collected and shared by national authorities to implement public services for safety, monitoring and control purposes. Within this context, governments have a privileged access through competent public bodies (especially through SafeSeaNet hosted by the European Maritime Safety Agency (EMSA)), and the use and sharing of this type of data by member states for MSP is regulated by Article 10 of MSP Directive 2014/89/EU. However, right now, this unencrypted data (non-anonymised) is also accessible to and exploited by private organisations (MarineTraffic, AISlive, etc.), who distribute and market it through online portals. In 2004, several shipping companies formed a group to express their concerns about the sharing of this type of data, mainly for security reasons (MSC 79/5/10). However, more than 10 years later, the websites in question are still online. 
Questions have also been raised about the use of personal data (natural persons). Regulation (EC) no. $1224 / 2009$ on fisheries mentions that personal data protection rights must be respected (Art. 112). The use of such data is regulated by EU law: Regulation (EU) no. 2016/679 on the protection of natural persons and regulating the processing, exchange and distribution of data and replacing, as of 25 May 2018, Directive 95/46/EC dated 24 October 1995 on the protection of natural persons with regard to the processing of personal data and on the free movement of such data. Even if monitoring systems such as AIS mainly concern legal persons (companies), they may also involve personal data, especially for fishing and leisure navigation (AIS B) activities, where a link can be made to the natural person owning the boat (European Commission, 2009). As a rule, the use of personal data requires consent from the natural person (Art. 6 of Regulation 2016/679). This type of request is actually very rarely made before AIS data is exploited. However, exceptions can be made for scientific research, though these are subject to certain conditions and may involve data pseudonymisation (Art. 5 and 89(1) of Regulation 2016/679). The question of commercial data confidentiality may also be raised. In the case of fishing, Regulation (EC) no. 1224/2009 states that collecting this type of data is subject to the applicable rules on professional and commercial secrecy of data (Art. 113). Yet, compared with VMS, respecting commercial confidentiality is not as straightforward when using AIS due to its accessibility and the fact that data is not encrypted. Finally, it is also important to note that an AIS data supplier may request that a license to use such data be signed to limit its use (for example, reproduction, re-use, publishing, or creation of derived or enriched data may not be authorised). This legal framework needs to be taken into account when exploiting AIS data. This is especially true not only for private initiatives on the fringes of public policy, but also for research programmes or projects supporting official MSP initiatives.

Despite these technical and legal obstacles, today, AIS data offers promising perspectives for both implementing MSP and evaluating the cumulative pressures and impacts (Barbanti et al., 2015; Fernandes et al., 2017), with the European Marine Strategy Framework Directive (Directive 2008/56/EC) in mind. With a view to developing a forward-looking spatialised approach based on scenarios, simulation prototypes based on multi-criteria (environmental, legal, socio-economic) modelling and on integrating AIS data may be used to predict the effects (positive, negative or neutral) on maritime traffic of introducing a new activity (e.g., MRE). 
Barbanti, A., Campostrini, P., Musco, F., Sarretta, A., Gissi, E., 2015. Developing a Maritime Spatial Plan for the Adriatic lonian Region. CNR-ISMAR, Venice, IT.

Brody, S.D., Grover, H., Bernhardt, S., Tang, Z., Whitaker, B., Spence, C., 2006. Identifying Potential Conflict Associated with Oil and Gas Exploration in Texas State Coastal Waters: A Multicriteria Spatial Analysis. Environmental Management 38, 597-617. https://doi.org/10.1007/s00267-005-0265-4

Campbell, M.S., Stehfest, K.M., Votier, S.C., Hall-Spencer, J.M., 2014. Mapping fisheries for marine spatial planning: Gear-specific vessel monitoring system (VMS), marine conservation and offshore renewable energy. Marine Policy 45, 293-300. https://doi.org/10.1016/j.marpol.2013.09.015

Christie, N., Smyth, K., Barnes, R., Elliott, M., 2014. Co-location of activities and designations: A means of solving or creating problems in marine spatial planning? Marine Policy 43, 254-261. https://doi.org/10.1016/j.marpol.2013.06.002

Coomber, F.G., D'Incà, M., Rosso, M., Tepsich, P., Notarbartolo di Sciara, G., Moulins, A., 2016. Description of the vessel traffic within the north Pelagos Sanctuary: Inputs for Marine Spatial Planning and management implications within an existing international Marine Protected Area. Marine Policy 69, 102-113. https://doi.org/10.1016/j.marpol.2016.04.013

Ehler, C., Douvere, F., 2009. Marine spatial planning, a step-by-step approach towards ecosystem-based management. (Report). UNESCO.

Etienne, L., Devogele, T., Bouju, A., 2012. Spatio-temporal trajectory analysis of mobile objects following the same itinerary, in: Advances in Geo-Spatial Information Science, International Society for Photogrammetry and Remote Sensing (ISPRS) Book Series. CRC Press, pp. 47-57. https://doi.org/10.1201/b12289-8

European Commission, 2009. Legal aspects of maritime monitoring \& surveillance data - Inland-waterway and sea transport - EU Bookshop (Summary report). Directorate-General for Maritime Affairs and Fisheries.

Fernandes, M., Esteves, T., Oliveira, E., Alves, F., 2017. How does the cumulative impacts approach support Maritime Spatial Planning? Ecological Indicators 73, 189-202. https://doi.org/10.1016/j.ecolind.2016.09.014

Gimpel, A., Stelzenmüller, V., Cormier, R., Floeter, J., Temming, A., 2013. A spatially explicit risk approach to support marine spatial planning in the German EEZ. Marine Environmental Research 86, 56-69. https://doi.org/10.1016/j.marenvres.2013.02.013

Goerlandt, F., Kujala, P., 2011. Traffic simulation based ship collision probability modeling. Reliability Engineering \& System Safety, Special Issue on Safecomp 2008 96, 91-107. https://doi.org/10.1016/j.ress.2010.09.003

Gourmelon, F., Le Guyader, D., Fontenelle, G., Levrel, H., Tissot, C., Bonneau De Beaufort, L., Rouan, M., 2013. Modélisation et scénarisation des activités humaines en rade de Brest (Research Report).

Guichoux, Y., Lennon, M., Thomas, N., 2016. Sea surface currents calculation using vessel tracking data, in: Maritime Knowledge Discovery and Anomaly Detection Workshop Proceedings. Ispra, Joint Resarch Centre (JRC).

Halpern, B.S., Walbridge, S., Selkoe, K.A., Kappel, C.V., Micheli, F., D’Agrosa, C., Bruno, J.F., Casey, K.S., Ebert, C., Fox, H.E., Fujita, R., Heinemann, D., Lenihan, H.S., Madin, E.M.P., Perry, M.T., Selig, E.R., Spalding, M., Steneck, R., Watson, R., 2008. A Global Map of Human Impact on Marine Ecosystems. Science 319, 948-952. https://doi.org/10.1126/science.1149345

Haslett, S., 2000. Coastal Systems. Routledge.

Hintzen, N.T., Bastardie, F., Beare, D., Piet, G.J., Ulrich, C., Deporte, N., Egekvist, J., Degel, H., 2012. VMStools: Open-source software for the processing, analysis and visualisation of fisheries logbook and VMS data. Fisheries Research 115-116, 3143. https://doi.org/10.1016/j.fishres.2011.11.007

IALA, 2004. IALA Guideline N ${ }^{\circ} 1028$ - The Automatic Identification System (AIS) Volume 1, Part 1 Ooperational Issues - Edition 1.3 [WWW Document]. Scribd. URL https://fr.scribd.com/document/59215034/lala-Ais-Guidelines-Vol1-Pt1-Ops-1-3 (accessed 5.7.17).

Jalkanen, J.-P., Johansson, L., Kukkonen, J., 2014. A Comprehensive Inventory of the Ship Traffic Exhaust Emissions in the Baltic Sea from 2006 to 2009. AMBIO 43, 311-324. https://doi.org/10.1007/s13280-013-0389-3

Jennings, S., Lee, J., 2012. Defining fishing grounds with vessel monitoring system data. ICES J Mar Sci 69, 51-63. https://doi.org/10.1093/icesjms/fsr173

Koehn, J.Z., Reineman, D.R., Kittinger, J.N., 2013. Progress and promise in spatial human dimensions research for ecosystem-based ocean planning. Marine Policy 42, 31-38. https://doi.org/10.1016/j.marpol.2013.01.015

Le Guyader, D., 2012. Modélisation des activités humaines en mer côtière (phdthesis). Université de Bretagne occidentale - Brest.

Le Guyader, D., Brosset, D., Gourmelon, F., 2012. Exploitation de données AIS pour la cartographie du transport maritime. M@ppemonde 104, http-mappemonde.

Le Guyader, D., Le Tixerant, M., Gourmelon, F., 2016. Dynamiques des ACTivités mARItimes (DACTARI) : Base d'Information Géographique et Temporelle en support à la connaissance et à la scénarisation (Research Report). CNRS LETG ; TerraMaris.

Le Guyader, D., Ray, C., Gourmelon, F., Brosset, D., 2017. Defining high-resolution dredge fishing grounds with Automatic Identification System (AIS) data. Aquat. Living Resour. 30, 39. https://doi.org/10.1051/alr/2017038

Le Tixerant, M., Gourmelon, F., Tissot, C., Brosset, D., 2010. Modelling of human activity development in coastal sea areas. Journal of Coastal Conservation 15, 407-416. https://doi.org/10.1007/s11852-010-0093-4

Leboeuf, C., Proutière-Maulion, G., 2013. Technicisation du suivi et du contrôle des navires de pêche : la mise en place simultanée des systèmes AIS et VMS. Droit Maritime Français 746.

Lee, J., South, A.B., Jennings, S., 2010. Developing reliable, repeatable, and accessible methods to provide high-resolution estimates of fishing-effort distributions from vessel monitoring system (VMS) data. ICES J Mar Sci 67, 1260-1271. https://doi.org/10.1093/icesjms/fsq010

Loretta, A., 2016. AIS: New OG2 Satellites Enable Near Real-Time Vessel Monitoring. ORBCOMM Blog.

Maes, F., De Batist, M., Van Lancker, V., Leroy, D., Vincx, M., 2005. Towards a Spatial Structure Plan for Sustainable Management of the Sea: Mixed actions - Final report: SPSD II (MA/02/006).

McCauley, D.J., Woods, P., Sullivan, B., Bergman, B., Jablonicky, C., Roan, A., Hirshfield, M., Boerder, K., Worm, B., 2016. Ending hide and seek at sea. Science 351, 1148-1150. https://doi.org/10.1126/science.aad5686

Mills, C.M., Townsend, S.E., Jennings, S., Eastwood, P.D., Houghton, C.A., 2007. Estimating high resolution trawl fishing effort from satellite-based vessel monitoring system data. ICES J Mar Sci 64, 248-255. https://doi.org/10.1093/icesjms/fsl026

Natale, F., Gibin, M., Alessandrini, A., Vespe, M., Paulrud, A., 2015. Mapping Fishing Effort through AIS Data. PLOS ONE 10, e0130746. https://doi.org/10.1371/journal.pone.0130746

Nicolas, F., Frias, M., Backer, H., 2016. Mapping maritime activities within the Baltic Sea (Report), Baltic SCOPE.

Pallotta, G., Vespe, M., Bryan, K., 2013. Vessel Pattern Knowledge Discovery from AIS Data: A Framework for Anomaly Detection and Route Prediction. Entropy 15, 2218-2245. https://doi.org/10.3390/e15062218

Pelot, R., Plummer, L., 2008. Spatial analysis of traffic and risks in the coastal zone. J Coast Conserv 11, 201. https://doi.org/10.1007/s11852-008-0026-7

Piante, C., Ody, D., 2015. Blue Growth in the Mediterranean Sea: the Challenge of Good Environmental Status. Medtrends Project (Report). WWF-France. 
Queffelec, B., Maes, F., 2013. Improving Sea-Land Management by Linking Maritime Spatial Planning and Integrated Coastal Zone Management: French and Belgian Experiences. Ocean Yearbook Online 27, 147-170. https://doi.org/10.1163/2211600190000158

Russo, T., D’Andrea, L., Parisi, A., Martinelli, M., Belardinelli, A., Boccoli, F., Cignini, I., Tordoni, M., Cataudella, S., 2016. Assessing the fishing footprint using data integrated from different tracking devices: Issues and opportunities. Ecological Indicators 69, 818827. https://doi.org/10.1016/j.ecolind.2016.04.043

Shelmerdine, R.L., 2015. Teasing out the detail: How our understanding of marine AIS data can better inform industries, developments, and planning. Marine Policy 54, 17-25. https://doi.org/10.1016/j.marpol.2014.12.010

Souza, E.N. de, Boerder, K., Matwin, S., Worm, B., 2016. Improving Fishing Pattern Detection from Satellite AIS Using Data Mining and Machine Learning. PLOS ONE 11, e0158248. https://doi.org/10.1371/journal.pone.0158248

St. Martin, K., Hall-Arber, M., 2008. The missing layer: Geo-technologies, communities, and implications for marine spatial planning. Marine Policy 32, 779-786. https://doi.org/10.1016/j.marpol.2008.03.015

Stelzenmüller, V., Diekmann, R., Bastardie, F., Schulze, T., Berkenhagen, J., Kloppmann, M., Krause, G., Pogoda, B., Buck, B.H., Kraus, G., 2016. Co-location of passive gear fisheries in offshore wind farms in the German EEZ of the North Sea: A first socio-economic scoping. Journal of Environmental Management. https://doi.org/10.1016/j.jenvman.2016.08.027

Strahler, A.N., 1957. Quantitative analysis of watershed geomorphology. Eos Trans. AGU 38, 913-920. https://doi.org/10.1029/TR038i006p00913

Vespe, M., Gibin, M., Alessandrini, A., Natale, F., Mazzarella, F., Osio, G.C., 2016. Mapping EU fishing activities using ship tracking data. Journal of Maps 12, 520-525. https://doi.org/10.1080/17445647.2016.1195299

Wichorowski, M., Katarzyna, F., Marek, Z., 2011. Data exchange structure for Maritime Spatial Planning - BaltSeaPlan Report 20 (Report). 